IJPDLM

47,10

992

Received 30 December 2016

Revised 10 May 2017

16 June 2017

Accepted 3 August 2017

\section{D printing the future: scenarios for supply chains reviewed}

\author{
Michael J. Ryan, Daniel R. Eyers, Andrew T. Potter, Laura Purvis and \\ Jonathan Gosling \\ Logistics and Operations Management Section, \\ Cardiff Business School, Cardiff University, Cardiff, UK
}

\begin{abstract}
Purpose - The purpose of this paper is to evaluate the existing scenarios for 3D printing (3DP) in order to identify the "white space" where future opportunities have not been proposed or developed to date. Based around aspects of order penetration points, geographical scope and type of manufacturing, these gaps are identified.

Design/methodology/approach - A structured literature review has been carried out on both academic and trade publications. As of the end of May 2016, this identified 128 relevant articles containing 201 future scenarios. Coding these against aspects of existing manufacturing and supply chain theory has led to the development of a framework to identify "white space" in the existing thinking.

Findings - The coding shows that existing future scenarios are particularly concentrated on job shop applications and pull-based supply chain processes, although there are fewer constraints on geographical scope. Five distinct areas of "white space" are proposed, reflecting various opportunities for future 3DP supply chain development.

Research limitations/implications - Being a structured literature review, there are potentially articles not identified through the search criteria used. The nature of the findings is also dependent upon the coding criteria selected. However, these are theoretically derived and reflect important aspect of strategic supply chain management.

Practical implications - Practitioners may wish to explore the development of business models within the "white space" areas.

Originality/value - Currently, existing future 3DP scenarios are scattered over a wide, multi-disciplinary literature base. By providing a consolidated view of these scenarios, it is possible to identify gaps in current thinking. These gaps are multi-disciplinary in nature and represent opportunities for both academics and practitioners to exploit.
\end{abstract}

Keywords Logistics, Additive manufacturing, Scenario planning, Gap analysis

Paper type Research paper

\section{Introduction}

There is an ongoing discussion as to how $3 \mathrm{D}$ printing (3DP) might evolve over the coming years, and how 3DP systems may be implemented and integrated into manufacturing systems. While Rogers et al. (2016) provide an overview of existing practices, the technologies of 3DP are advancing rapidly and when looking to the future, scenario planning approaches can make a valuable contribution (e.g. Birtchnell and Urry, 2013; Potstada and Zybura, 2014). These techniques are particularly useful in prediction for emerging technologies, as they present a series of alternative possibilities for the future rather than trying to attempt to predict a definitive outcome, allowing investigation of future performance if any of these outcomes should occur (Schoemaker and Mavaddat, 2000).

(C) Michael J. Ryan, Daniel R. Eyers, Andrew T. Potter, Laura Purvis and Jonathan Gosling. Published by Emerald Publishing Limited. This article is published under the Creative Commons Attribution (CC BY 4.0) licence. Anyone may reproduce, distribute, translate and create derivative works of this article (for both commercial and non-commercial purposes), subject to full attribution to the original publication and authors. The full terms of this licence may be seen at http://creativecommons.org/ licences/by/4.0/legalcode

The authors wish to acknowledge Cardiff Business School for their funding of the "Engaged Manufacturing" Project. 
With such a variety of predictions in published 3DP literature (often reflecting a diverse disciplinary base examining the opportunities with this technology), there is a need to evaluate and synthesise these existing scenarios to identify common components drawn from established supply chain theory. In doing so, gaps (which we term "white space", reflecting Frankel et al., 2005) in existing thinking on future 3DP scenarios can be identified, driving future research opportunities.

The aim of this paper is therefore to identify the "white space" in existing 3DP scenario proposals, examining the supply chain implications and considering the possibilities for 3DP to fill this gap. A framework for codifying 3DP scenarios is developed and the "white spaces" within this framework are those where few/no existing scenarios were found. This paper therefore makes two main contributions to the literature: the first provides a framework that captures the underlying features of current 3DP supply chains, and the second develops a future research agenda that expands supply chain thinking on the opportunities for 3DP.

The starting point for the research was exploratory in the 3DP field, examining a sample of existing literature (both on 3DP and scenario planning) as well as engaging with practitioners through interviews and attendance at trade events. This identified both common and distinguishing features in future 3DP scenarios, and informed the development of the coding criteria for the structured literature review. Although not part of the formal method for this research, the exploratory stage helped to frame our understanding of the area, which is elucidated the following two sections below.

The main focus for addressing the aim was a structured literature review, informed by established procedures in the works of Tranfield et al. (2003) and Saenz and Koufteros (2015) amongst others. Details of this can be found in the Method section. There then follows the analysis, establishing where existing scenarios have been developed, which is then extended to identify where "white space" in future 3DP supply chain thinking exists. A future research agenda is proposed, leading to final conclusions being drawn.

\section{Scenario planning for supply chain management}

Being an innovative technology, the full range of applications of 3DP has still to be realized. Consequently, scenario development and planning approaches are often used to provide alternative views of future uses and applications of this technology within an applied context. Scenario development and planning was popularised by Royal Dutch Shell in the 1970s and differs from other planning methods, in that rather than trying to determine a definite outcome for the future, it aims to develop a range of possible futures (Schwarz, 1991). Importantly, scenarios examine the "external environment; that is the environment within which an organisation operates" (O’Brien, 2004). In doing so, they consider the relationships between uncertainties, trends and the behaviour of actors involved in the scenario (Wright and Cairns, 2011). By developing scenarios, organisations can plan for development against various possible futures, refining the scenarios further as time goes on and future reality becomes clearer (Schoemaker and Mavaddat, 2000). Bishop et al. (2007) document a wide range of available techniques for generating scenarios, ranging from a "genius" approach based largely on expert judgement, to more structured techniques such as probability trees.

Within the context of supply chain management, the importance and application of scenario planning has been highlighted by both academics and practitioners. From a strategic perspective, Sodhi (2003) suggests using scenario planning to develop a strategic view of the supply chain, before using modelling approaches to consider tactical and operational decisions. Such an approach is also discussed in the works of both Van Landeghem and Vanmaele (2002) and Shapiro (2004). However, Von Der Gracht and Darkow (2010) also highlight a lack of use of scenario planning within the logistics industry, providing a useful
3D printing the future 
IJPDLM

47,10

994

review of papers that do use such an approach. They then proceed to develop some future scenarios, drawing on insights from experts, students and other academics. Further, Darkow (2015) applied scenario planning as a means to engage middle managers in supply chain strategy development within a multinational chemical products firm. From a practical perspective, several organisations have developed visions of future supply chains including CILT (2011) and DHL (2012). In both reports, 3DP is identified as a technology that may significantly change supply chain practices in the future.

Beyond this work that formally adopts a scenario planning approach, there are also many publications that informally develop one or more scenarios for future supply chains. In a 3DP context, examples include Silva and Rezende (2013), Liu et al. (2014), Jia et al. (2016) and Jiang et al. (2017). Given that such 3DP literature appears to be scattered across a range of disciplinary boundaries, there is a need to provide a more consolidated view to identify the underlying features of these scenarios that will shape such supply chains of the future. We achieve this by reviewing scenarios proposed through the existing literature, and analysing the supply chain implications that might stem from them.

\section{Developing a coding framework for future additive manufacturing (AM) scenarios}

The implications for supply chains of the introduction of 3DP as a manufacturing technology are widespread, including effects upon transportation costs (Birtchnell et al., 2013; Barz et al., 2016), lead times (Holmström et al., 2010; Khajavi et al., 2015), inventory (Khajavi et al., 2014; Mavri, 2015), product quality and reliability (Monzon et al., 2015; Wagner and Walton, 2016) production flexibility, productivity and economies of scale (Petrick and Simpson, 2013; Baumers et al., 2016; Sasson and Johnson, 2016), supply chain sustainability (Chen et al., 2015; Ford and Despeisse, 2016), new business models (Rayna and Striukova, 2014) and opportunities for new suppliers (Bogers et al., 2016). This research, however, focusses on three areas: customer engagement, examined using OPP (Gosling et al., 2007), the geographic distribution of manufacturing and the type of manufacturing operation, each of which is described further in the following sections. Through the initial exploratory study and discussions with expert practitioners, these criteria were identified as those which commonly featured in, and yet consistently differentiated between the future proposals under examination, giving a strong indication of the nature of each scenario being proposed.

\section{Customer engagement in the supply chain}

One of the main advantages of 3DP cited in literature is its ability to support increased product customization (Tuck et al., 2008), which in turn requires the customer to be actively involved in the definition of their product (Duray et al., 2000). This involvement can be achieved at different stages of the fulfilment process (Lampel and Mintzberg, 1996), and within supply chain management literature is typically identified in terms of its order penetration point (OPP). OPPs are first described in the work of Sharman (1984) as "the point where product specifications get frozen", and the strategic selection of different OPPs can affect the nature of customization achieved through different supply chain structures. Gosling et al. (2007) identify six different OPP possibilities and their associated supply chain structured, and this therefore represents six different points at which the customer may become engaged in the supply chain (Figure 1). This approach covers situations from ship-to-stock (STS), where customisation is reserved until the final point of distribution onwards, through to engineer-to-order (ETO), where complete customization takes place from the onset of the design and manufacture of the product. In the case of 3DP, literatures such as Ostuzzi et al. (2015) and Scholz et al. (2016), emphasise the ETO 


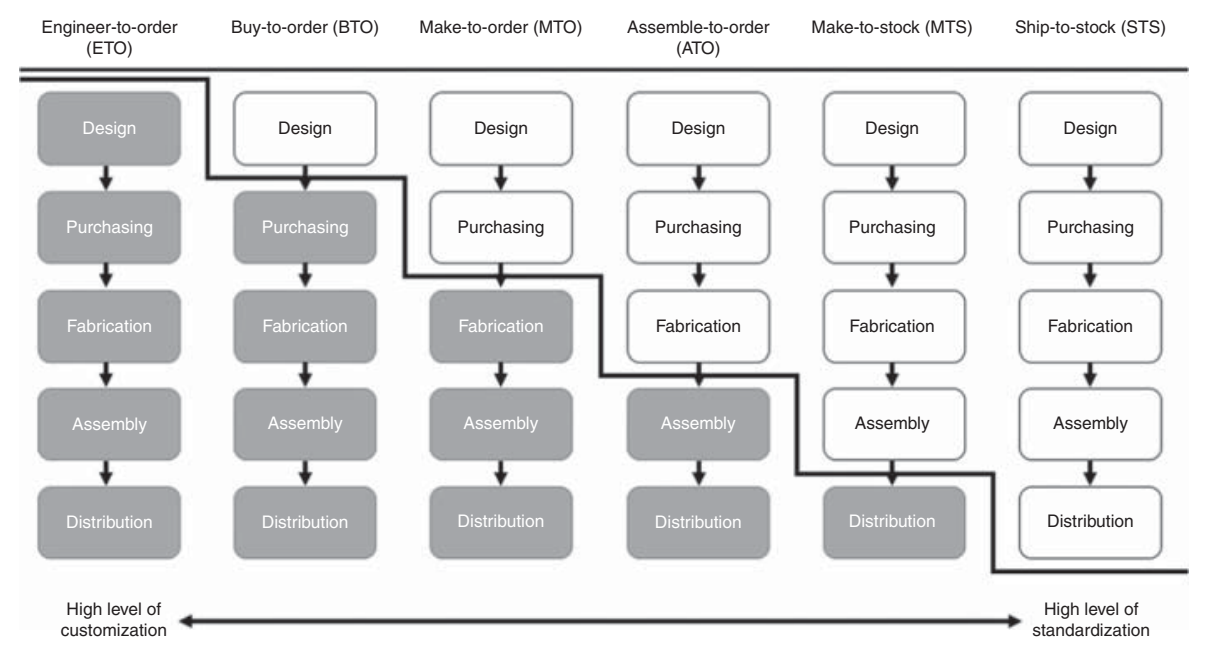

3D printing the future

Source: Adapted from Gosling et al. (2007)

capabilities that 3DP technology enables, however many other examples exist, examining other regions of this spectrum, such as make-to-order (MTO) (Scott and Harrison, 2015), and even make-to-stock (MTS) (Eyers, 2015) applications of 3DP. In this study we therefore avail of Gosling et al. (2007) to provide six categories (ETO, buy-to-order (BTO), MTO, assemble-to-order (ATO), MTS, STS) through which we codify the AM literature.

\section{Manufacturing distribution}

Various degrees of geographic distribution for manufacturing are readily identifiable within the 3DP industry (Rogers et al., 2016). These range from discussions around a future where consumers have printers at home, manufacturing one-off items as and when required (e.g. The Economist, 2011) to large-scale factory environments operating at a national level (e.g. Eyers, 2015). Between these extremes, there are many examples where more redistributed manufacturing is proposed, both at a local (Bedinger et al., 2016), and a regional level (Sasson and Johnson, 2016). The use of 3DP in local (or redistributed) manufacturing has been identified to be of particular interest in relation to government support for reshoring of manufacturing as a means of national competitiveness (e.g. Moser, 2011) and also for practitioners in the field of local supply chains (e.g. CIPS Knowledge, 2013). Several proposals also exist which suggest that 3DP can be applied in mobile operations (Hargreaves, 2009).

More generally, geography plays an important role in defining a supply chain network. As Narasimhan and Carter (1990) note that the geography of a network can influence and be influenced by a range of supply chain decisions at strategic, tactical and operational levels. For example, within logistics it is common to see reference to regional and national distribution centres (Rushton et al., 2014). In a production context, comparisons between centralised and decentralised production systems are often linked to the geographical coverage provided by each node (Storper and Harrison, 1991), with the latter considered closer to the customer (Srai et al., 2016).

In this study, five categories have been selected and are defined as follows:

(1) Personal: manufactured in the end user's own home, at the point of final use. This is a special example of 3DP, since it involves the customer producing their own product, rather than engaging the services of a manufacturer (as seen in the other four categories). 
IJPDLM

47,10

996
(2) Local: manufacturing is distributed with many production facilities. Manufacturing takes place near to the final point of use.

(3) Regional: a degree of manufacturing distribution is observed, but with fewer facilities, each serving a geographic region.

(4) National: a single, centralised production facility supplying a large geographic area.

(5) Mobile: The manufacturing equipment is portable. 3DP machines are either taken to the point of end-use, where manufacturing takes place, or manufacturing takes place in transit.

\section{Manufacturing operation types}

There are also significant variations in the proposed manufacturing operations. With such a wide variety of $3 \mathrm{DP}$ technologies now commercially available, there are clear differences in the types of operations which can be built around 3DP production. 3DP machines range from small desktop printers costing a few hundred dollars, and able to produce plastic components of a limited quality, to high quality, high precision industrial machines which cost multiple hundreds of thousands of dollars and can produce parts from materials including plastics, metals and ceramics (Wohlers and Caffrey, 2015).

Over time, there has been an evolution in the approaches taken for manufacturing (Cusumano, 1992). Early production systems were based around craft production, where a skilled artisan would produce items for the local market in which they were based. As the ability to produce in larger volumes has emerged, so there has been a move towards job shops and, with the industrial revolution factory-based production systems. The result is a continuum of different production environments, as embodied in the product-process matrix of Hayes and Wheelwright (1979). Such frameworks are often predicated on volume and variety requirements, which also then have an influence on the OPP. However, it is claimed that 3DP will enable these trade-offs to be overcome (Eyers, 2015) and therefore examining the extent to which this has been considered within existing scenarios will be valuable.

In the coding criteria, these different operations have been identified, namely:

(1) Craft, where (in the case of 3DP) low-cost equipment is used to produce low volumes of products. In this type of operation, the equipment usually operated by the end user of the product.

(2) Job shop, defined by Reiter (1966) as "a collection of specific skills and equipment which stands ready to sell its services to customers on order", where the volume of production remains low, but the equipment is of far higher cost and quality, and operators are specialists.

(3) Factory, where production volumes are high, the equipment is specialized and operators are trained in its use. In this situation, manufacturing procedures are standardized, and so operator skill levels do not need to be as high as in other operations.

\section{Method}

This study employs a structured literature review to evaluate potential scenarios for 3DP already proposed in the literature. Unlike traditional narrative, literature reviews that can be affected by author bias (Tranfield et al., 2003), the structured approach provides a detailed explanation of the literature base searched and how it was analysed in the provision of a robust investigation. Saenz and Koufteros (2015) provide guidance on the best practice for the construction of structured literature reviews, and these have been 
instrumental in the development of the review process. We also draw heavily on the guidance of Tranfield et al. (2003) in definition of the literature review, and Seuring and Gold (2012) in the analysis of publications.

\section{Structured literature review}

A pilot study of the literature was conducted, and in-line with Saenz and Koufteros (2015), experts in AM were consulted to develop a robust search strategy. This initial investigation led to the process in Figure 2 being conducted to identify the literature sample for analysis. Search term "A" served to frame the review for 3DP, and included two relevant synonyms that are often used in literature. Search term "B" allowed an explicit focus on articles that described or mentioned scenarios. Using these parameters, full-text searches were conducted on six major databases that have been selected based on their coverage of pertinent academic journals and trade publications. As shown in Table I, the literature search yielded 1,451 unique publications (1,922 prior to the exclusion of duplicates), as at 31 May 2016. Any automated filtering (such as by date, publication type or journal ranking) was discounted, as this either eliminated very few papers, which could therefore be included in the manual filtering process, or eliminated too high a proportion of the search findings. However, only those articles with full-text available immediately (electronically, or available in the University Library System) were included in the review, leaving a final sample of 1,392 publications that were reviewed in this work. As 3DP applications are often innovative, significant numbers of relevant articles were found in both press and industrial publications, and not just academic publications. Consequently, no restrictions were placed on the type of publication.

\section{Coding and compilation of results}

Each of the 1,392 articles underwent an initial review process to identify its suitability for further analysis. An initial review of abstracts was undertaken, to determine whether each paper contained relevant content (i.e. containing information regarding future 3DP scenarios) and applying context to these applications. Where the relevance of the content could not be clearly determined from the abstract, the paper was retained for

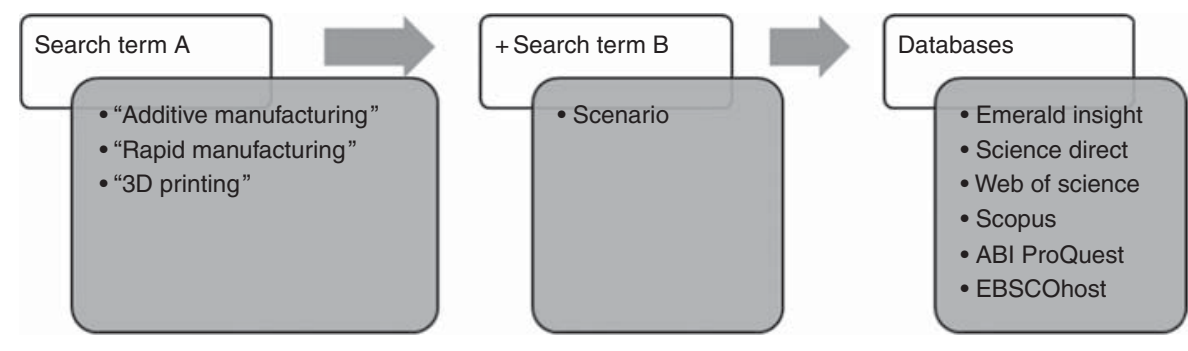

Database

\begin{tabular}{|c|c|c|c|c|c|c|c|c|}
\hline Search term & $\begin{array}{c}\text { Emerald } \\
\text { Insight }\end{array}$ & $\begin{array}{c}\text { Science } \\
\text { Direct }\end{array}$ & $\begin{array}{l}\text { Web of } \\
\text { Science }\end{array}$ & Scopus & $\begin{array}{c}\text { ABI } \\
\text { ProQuest }\end{array}$ & EBSCOhost & $\begin{array}{c}\text { Total } \\
\text { number } \\
\text { of articles }\end{array}$ & \\
\hline "Additive Manufacturing” + Scenario & 53 & 336 & 27 & 106 & 140 & 1 & 663 & \\
\hline "Rapid Manufacturing" + Scenario & 33 & 124 & 7 & 77 & 91 & 0 & 332 & Table I. \\
\hline "3D Printing" + Scenario & 61 & 503 & 27 & 128 & 204 & 4 & 927 & Details of literature \\
\hline Total number of articles & 147 & 963 & 61 & 311 & 435 & 5 & 1,922 & search findings \\
\hline
\end{tabular}

3D printing the future

Figure 2. structure
Literature review 
IJPDLM 47,10

998

Figure 3.

Work flow for structured literature review full-text analysis. Consequently, 431 papers were retained for further examination, and the contents of these compared against the coding framework outlined earlier. Some publications provided scant detail in their discussion, and were therefore rejected for inclusion due to their minimal contribution. Articles that stated no more than suggested applications for the technology (e.g. "3DP will be used to produce medical implants") and offered no real insights for operations or supply chains, and were not included in the review. By comparison, articles that provide context (e.g. "3DP will be used to produce medical implants in the hospital operating room" or "3DP factories producing medical implants will exist in every town") offer sufficient information to make a valuable contribution to the study. A schematic of the process carried out is shown in Figure 3.

Following this review process, 128 relevant articles were identified as suitable for inclusion in the literature review and each was re-read in depth and evaluated using coding framework, and summarised in Table II. Where multiple scenarios were presented in a single publication they were recorded as separate entities. Consequently, 201 relevant scenarios were found within the literature, giving a wide variety of outcomes, possible 3DP applications, and covering a wide variety of products. Analysis of the outputs from the structured review included frequency counts on many of the coded variables. Two-way tables also highlighted connections between variables while the "white space" of 3DP scenarios was visualised through a three-dimensional framework.

To support quality in the assessment process, a detailed spreadsheet was compiled to maintain the results of the review. In addition to basic citation data and details from the coding process, additional data were gathered (where available) to note focal products, envisaged suitability of 3DP processes, identified timetables for implementation and any noted supply chain effects. Recognising the importance of the methods employed in development of the scenarios, we also recorded details of the approaches taken by the authors. An example of how these criteria were applied to the literature is given in Table III. Coding was initially conducted by a single researcher,

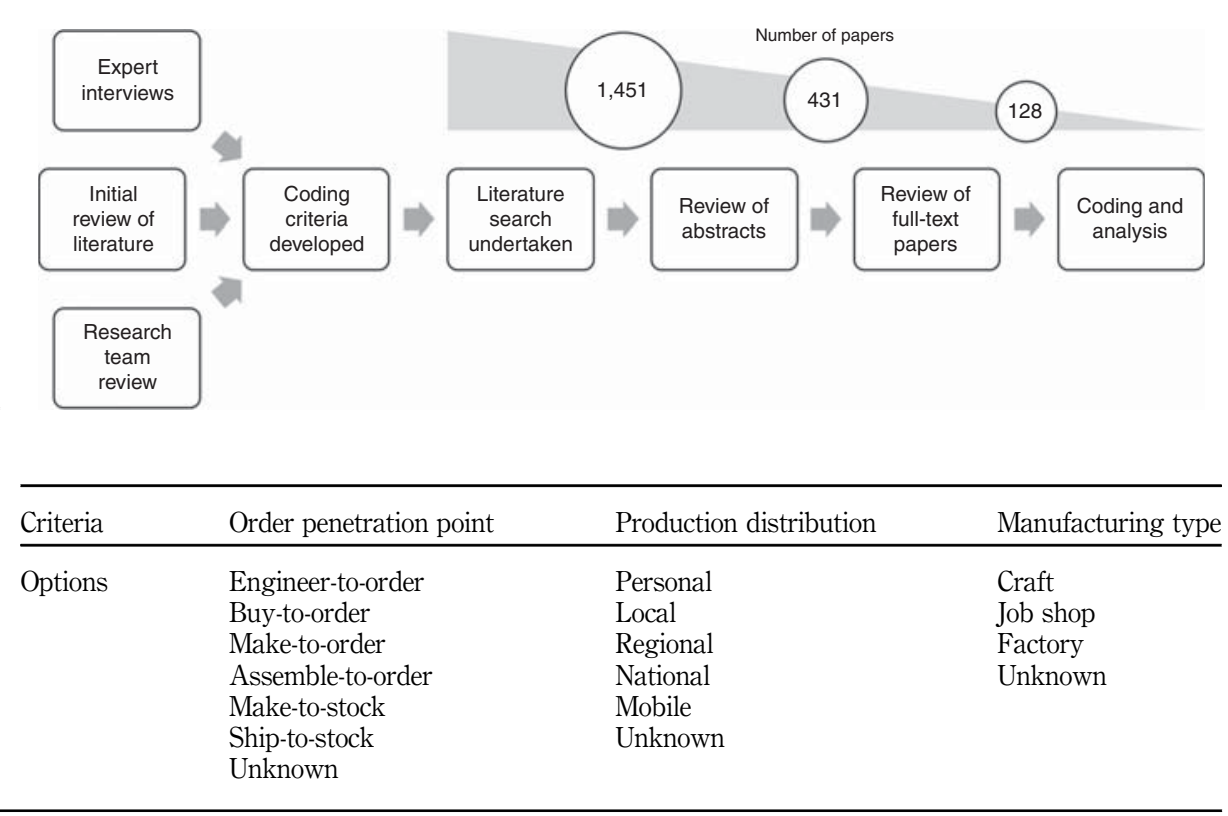

\begin{tabular}{llll}
\hline Criteria & Order penetration point & Production distribution & Manufacturing type \\
\hline \multirow{2}{*}{ Options } & Engineer-to-order & Personal & Craft \\
& Buy-to-order & Local & Job shop \\
& Make-to-order & Regional & Factory \\
& Assemble-to-order & National & Unknown \\
& Make-to-stock & Mobile & \\
Ship-to-stock & Unknown & \\
& Unknown & &
\end{tabular}

Table II.

Coding criteria for literature evaluation 


\begin{tabular}{|c|c|c|c|c|c|}
\hline Publication & Quotations & $\begin{array}{l}\text { Order penetration } \\
\text { point }\end{array}$ & $\begin{array}{l}\text { Production } \\
\text { distribution }\end{array}$ & $\begin{array}{l}\text { Manufacturing } \\
\text { type }\end{array}$ & the future \\
\hline \multirow[t]{2}{*}{$\begin{array}{l}\text { Potstada and } \\
\text { Zybura } \\
\text { (2014, pp. } \\
101-114)\end{array}$} & \multirow{2}{*}{$\begin{array}{l}\text { "Products can be edited according } \\
\text { to individual preferences and the } \\
\text { result is immediately observable. } \\
\text { Selecting a product of choice offers } \\
\text { a multitude of features to choose } \\
\text { from. Every option desired in CE, } \\
\text { such as where buttons should be } \\
\text { located and which form a device } \\
\text { should ideally have, can be } \\
\text { perfectly harmonised" } \\
\text { "As most products are home- } \\
\text { fabricated (except for bigger } \\
\text { devices that are fabricated at } \\
\text { printing hubs in the vicinity), they } \\
\text { can be ordered and self-designed in } \\
\text { virtual show rooms and } \\
\text { immediately produced ready for } \\
\text { use at home" }\end{array}$} & \multirow[t]{2}{*}{$\begin{array}{l}\text { Engineer-to-order: } \\
\text { Design is produced } \\
\text { specifically for each } \\
\text { customer }\end{array}$} & \multirow[t]{2}{*}{$\begin{array}{l}\text { Personal: } \\
\text { Products are } \\
\text { manufactured } \\
\text { at home }\end{array}$} & \multirow{2}{*}{$\begin{array}{l}\text { Craft: } \\
\text { Only small-scale } \\
\text { products can be } \\
\text { produced on } \\
\text { such a system - } \\
\text { reminiscent of } \\
\text { current desktop } \\
\text { printers }\end{array}$} & 999 \\
\hline & & & & & \\
\hline $\begin{array}{l}\text { Nickels } \\
\text { (2015, pp. } \\
300-303)\end{array}$ & $\begin{array}{l}\text { "In future, it may be possible to } \\
\text { additive manufacture spare parts } \\
\text { on demand in decentralised } \\
\text { locations [..." } \\
\text { "In small size production, there can } \\
\text { also be cost reductions using AM" }\end{array}$ & $\begin{array}{l}\text { Make to order: } \\
\text { Existing designs } \\
\text { (spare parts) produced } \\
\text { when required }\end{array}$ & $\begin{array}{l}\text { Local: } \\
\text { Printed near to } \\
\text { the point of } \\
\text { demand }\end{array}$ & $\begin{array}{l}\text { Job shop: } \\
\text { Low volumes, } \\
\text { using } \\
\text { specialized } \\
\text { equipment }\end{array}$ & $\begin{array}{l}\text { Table III. } \\
\text { Examples of } \\
\text { coding activity }\end{array}$ \\
\hline
\end{tabular}

although the sample was further coded by members of the research team. Inter-coder agreement was achieved through discussions amongst all members of the research team (Seuring and Gold, 2012).

\section{Results}

\section{Overview of the sample}

Considering the temporal distribution of all 1,451 articles retrieved in the literature review, as shown in Figure 4, it is evident that relevant discussions have been occurring since the mid-1980s, though the quantity of these has been relatively low. However, since 2009 annual publications have increased rapidly, and a corresponding increase in the number of valid scenarios identified in the literature is evidenced. The 238 publications and 33 scenarios available between January and May 2016 suggest that the pattern is continuing, and it is likely that an even greater number of articles will be published in this area in 2016 than in any previous year.

To provide some context to the publication analysis, in Figure 4 we include some key dates in the development of 3DP (from Cotteleer and Deloitte Services LLP, 2014), and, based on the work of Wohlers and Caffrey (2015), revenue for 3DP products and services worldwide. It is notable that the rapid growth in publications from 2009 onwards corresponds with two important events in 3DP development. The first is the successful culmination of the "RepRap" project (Jones et al., 2011) to develop an "open source" 3D printer, and the second is the expiry of Crump and Stratasys, Inc.'s (1992) patent on the "fused deposition modelling" (FDM) process, on which the RepRap is based. Between them, these events have provided a technological base on which many inexpensive "desktop" 3D printers have been developed. Based mainly around FDM technology, entry-level printers cost from \$200 (All3DP, 2016), and although currently the quality and reliability of these 
IJPDLM

47,10

1000

Figure 4.

Number of search results per year

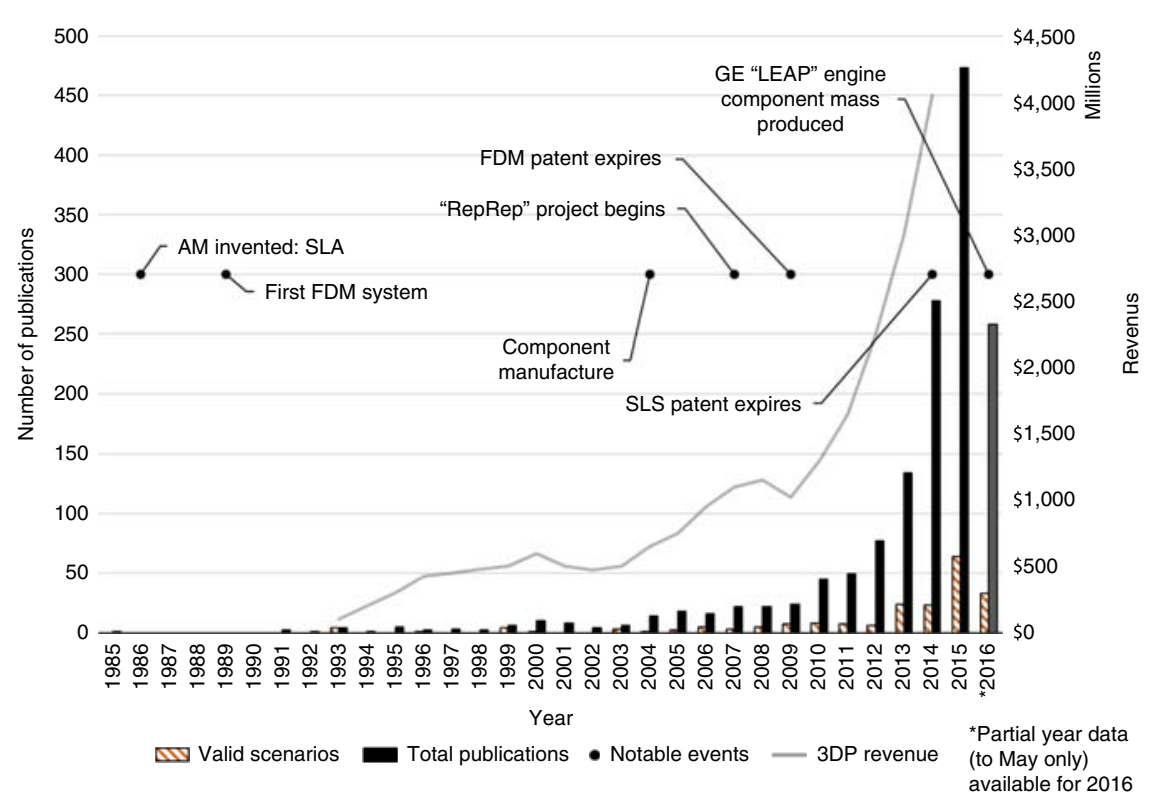

machines is far lower than professional equipment, manufacturing at home may be on the horizon (Birtchnell and Urry, 2013). As the technologies become increasingly widespread (evidenced by the market revenue data), more research is expected (evidenced by the number of publications), and new opportunities are likely to be posed in the literature (in the form of potential scenarios), suggesting an exciting future for 3DP research. Interestingly, these market developments have not led to significant changes over time in the concepts contained within the published scenarios.

Table IV shows the range of publications in which the scenarios are contained. This shows a wide diversity of outlets, including both practitioner (such as Industry Week and Metal Powder Report) and academic publications. In the academic realm, there is a strong influence from the engineering discipline. However, there is also evidence of publications in particularly the logistics/supply chain and innovation areas, showing how the consideration of 3DP is moving from technological developments to applications.

Although Bishop et al. (2007) state that the GBN/Royal Dutch Shell method is the most commonly used when producing future scenarios, in 164 (81.6 per cent) of the scenarios it appears that a "genius" approach to scenario development was adopted, relying on the judgement of the author(s) to develop the scenarios. In practice, this effectively means that the author adopts the role of an "expert", and makes their predictions for the future. In most cases, however, little detail was given of the method used. There were occasions, however, where more structured techniques, such as literature-based studies (e.g. Eyers and Potter, 2015), case studies (e.g. Noriega et al., 2010; Holmstrom and Partanen, 2014) and two-axis methods (e.g. Birtchnell and Urry, 2013) were adopted.

Evaluation of the effects of the scenarios was only undertaken in 17 per cent of those reviewed. A variety of different approaches were used, including supply chain simulations of systems to compare the use of 3DP against traditional manufacturing techniques (e.g. Chiu and Lin, 2016; Jia et al., 2016; Liu et al., 2014), analysis of environmental factors such as material and energy use (e.g. Senyana and Cormier, 2014; Chiu and Lin, 2016) and more qualitative approaches (e.g. Gebbe et al., 2015). It would appear, therefore, that there is 
Publication

Procedia CIRP

Rapid Prototyping Journal

Acta Astronautica

CIRP Annals - Manufacturing Technology

Journal of Manufacturing Systems

Technological Forecasting and Social Change

Computer-Aided Design

Futures

Robotics and Computer-Integrated Manufacturing

Computers in Industry

IFAC Proceedings Volumes

Industry Week

Journal of Cleaner Production

Journal of Humanitarian Logistics and Supply Chain Management

Machine Design

Mechanical Engineering

Metal Powder Report

Supply Chain Management: An International Journal

The Engineer

Urology
Type of publication $\quad$ No. of scenarios

Conference papers $\quad 7$

Academic journal

Academic journal

Academic journal

Academic journal

Academic journal

Academic journal

Academic journal

Academic journal

Academic journal

Conference papers

Trade publication

Academic journal

Academic journal

Trade publication

Trade publication

Trade publication

Academic journal

Trade publication

Academic journal
$3 \mathrm{D}$ printing

the future

1001

a need for further in-depth analysis of these proposals in order to determine which are feasibly, both in the long and short term.

The timescales for the implementation of these scenarios are rarely discussed in the literature, with a target year for their implementation only specified in 13 of the 201 scenarios. For those that did specify timescales, two scenarios were proposals for the date of publication, or the very near future, three proposals for 2024 to 2025, six for 2030 and one each for 2033 and 2038. Examining the publication dates of these papers, this shows a forecasting range of 15-17 years ahead of publication, with one exception of 19 years and one of 25 years.

\section{Mapping the 3DP scenario landscape}

In considering the nature of 3DP supply chains suggested in the scenarios, we now consider the OPP, the distribution and the type of manufacturing operation, as explained earlier. This enables an understanding of the existing landscape and therefore informs the identification of "white space" in future 3DP supply chain scenarios. Table V shows, for the criteria identified earlier, the number of scenarios coded against each value.

\begin{tabular}{lclrlr}
\hline \multicolumn{2}{l}{$\begin{array}{l}\text { Order penetration point } \\
\text { Options }\end{array}$} & No. of scenarios & \multicolumn{2}{l}{$\begin{array}{l}\text { Production distribution } \\
\text { Options }\end{array}$} & \multicolumn{2}{l}{ No. of scenarios } & \multicolumn{2}{l}{ Manufacturing type } \\
Ontions & No. of scenarios \\
\hline Engineer-to-order & $95(47.3 \%)$ & Personal & $28(13.9 \%)$ & Craft & $43(21.4 \%)$ \\
Buy-to-order & $19(9.5 \%)$ & Local & $77(38.3 \%)$ & Job shop & $118(58.7 \%)$ \\
Make-to-order & $69(34.3 \%)$ & Regional & $12(6.0 \%)$ & Factory & $25(12.4 \%)$ \\
Assemble-to-order & $7(3.5 \%)$ & National & $43(21.4 \%)$ & Unknown & $15(7.5 \%)$ \\
Make-to-stock & $6(3.0 \%)$ & Mobile & $11(5.5 \%)$ & & \\
Ship-to-stock & $0(0.0 \%)$ & Unknown & $30(14.9 \%)$ & & \\
Unknown & $5(2.5 \%)$ & & & & \\
& & & &
\end{tabular}

Table V. Results of literature coding
Table IV.

Publications containing 3DP

scenarios in literature review 
IJPDLM

47,10

1002
Examining the location of the OPP, Table V shows a strong tendency towards customised, on-demand production in the scenarios analysed, with an ETO approach proposed in almost half of the scenarios and MTO accounting for another third. Examples range from customised (ETO) medical implants produced on-site at a hospital (Srougi et al., 2016), to spare parts made to order (Ford and Despeisse, 2016). This is unsurprising, as it makes use of the inherent strengths of 3DP systems, such as low set-up costs allowing production to take place on-demand, and in low volumes (Schubert et al., 2014; Merrill, 2014). Production based around manufacturing approaches of this nature suggests a high level of customer involvement, with the OPP early in the design and manufacture process providing opportunities for the customer to become involved in the product's development. However, there are also some scenarios which suggest that 3DP can apply to a more standardised production environment (using ATO or MTS principles) - for example, using 3DP within a mass customization process (Ferguson et al., 2014), or to produce aircraft components for stock (Silva and Rezende, 2013). No scenarios considered a STS situation despite, as will be discussed shortly, mobile production being an opportunity for 3DP.

With regards to the type of manufacturing operation, there is a clear interest in job shop operations for 3DP, whilst factory production is the least commonly proposed. This is consistent with the findings of Rogers et al. (2016) in their review of existing European providers of 3DP services. There is a suggestion, therefore that 3DP will lead to smaller, and possibly more specialised operations than are seen to date, again making use of 3DP's ability to produce low volume, on-demand products cost-effectively (such as Silva and Rezende, 2013; Holmstrom and Partanen, 2014). The results could also suggest a shift away from mass production operations and towards more customizable products. It is also interesting to note that only 23 per cent of proposed scenarios are based around craft manufacturing operations, despite ongoing media hype that personal printing at home is likely to become common in the near future (e.g. Taylor, 2012; The Economist, 2011). Scenarios built around craft scenarios are largely unspecific around products, focussing more on the application, however there are some specific cases including, for example, personalised medical devices (Würtz et al., 2015; Pasluosta et al., 2015) and consumer goods and electronics (Easton, 2009).

Finally, Table $\mathrm{V}$ shows that local manufacturing is clearly the most commonly discussed option, representing 38 per cent of the proposals. This again complements the finding that the majority of scenarios are built around job-shop operations, suggesting scenarios are often building on existing models of practice (as illustrated in Rogers et al., 2016) rather than identifying new opportunities in the "white space". In some cases, this is taken as far as manufacturing at the point of use, such as creating pills at a pharmacy (Park, 2015), or manufacturing customised consumer goods directly in shops on the high street (Birtchnell and Urry, 2013). Manufacturing on a national scale is represented in 21 per cent of the proposals, possibly because low-demand volumes coupled with the niche nature of the technology (Anonymous, 2006) requires centralised facilities are envisaged. Again, despite media hype, personal production is only represented in 14 per cent of scenarios. This is less than the number of craft scenarios as the latter also includes the use of 3DP in small offices and workspaces. An interesting finding is the appearance of mobile manufacturing. Although there has been some research in this area with large, specialized "factory-in-a-box" applications (Stillstrom and Jackson, 2007), the general-purpose nature of 3DP machines (Garrett, 2014) could possibly allow a much wider application.

\section{Identifying the "white space" of 3DP supply chain scenarios}

In order to identify the "white space" of 3DP supply chain scenarios, we now consider the combinations of coding variables, to build a more complete picture of the scenarios which 
are being proposed. There are 90 possible combinations of factors for scenario creation, but only 27 of these possible combinations were found in the literature, as shown in Table VI and Figure 5.

Examining Figure 5 shows that there are clear clusters where research effort has been focussed in the past. Job shops offering customised production (ETO, BTO, MTO) are particularly popular and, while predominantly local in focus, there is some evidence of scenarios considering a more regional (Sasson and Johnson, 2016) or national (Cautela et al., 2014) focus. As noted earlier, such a focus overcomes issues around low-demand volumes and/or specialist technical knowledge. Craft-based production scenarios particularly emphasise the presence of 3DP machines in the home (e.g. Birtchnell and Urry, 2013) or locally, for example in libraries (Prince, 2014), with designs downloaded, modified (Birtchnell and Urry, 2013) or engineered by the user (Montelisciani et al., 2014) to suit a particular application before printing. Those more future-looking scenarios, such as Potstada and Zybura (2014) who have developed scenarios for 2033, suggest a virtual "shop" environment where designs can be purchased and tailored extensively before printing at home. Much of the factory-based research has been positioned at the national scale (e.g. Stuart and Excell, 2010; Achillas et al., 2015), reflecting the need for economies of scale or scope and covering the full spectrum of OPP scenarios.

Figure 5 also shows that there are significant areas where few/no scenarios have been developed to date, representing the "white space" that this paper seeks to identify. "White spaces" cover all aspects of one coding element (OPP, operation type or distribution), plus at least two aspects of a second element. Further, existing published

\begin{tabular}{|c|c|c|c|c|}
\hline Order penetration point & Distribution of manufacturing & Manufacturing type & Number of occurrences & \\
\hline Engineer-to-order & Personal & Craft & 16 & \\
\hline Engineer-to-order & Local & Craft & 9 & \\
\hline Engineer-to-order & Local & Job shop & 24 & \\
\hline Engineer-to-order & Local & Factory & 1 & \\
\hline Engineer-to-order & Regional & Job shop & 10 & \\
\hline Engineer-to-order & Regional & Factory & 1 & \\
\hline Engineer-to-order & National & Job shop & 13 & \\
\hline Engineer-to-order & National & Factory & 4 & \\
\hline Engineer-to-order & Mobile & Job shop & 2 & \\
\hline Buy-to-order & Personal & Craft & 3 & \\
\hline Buy-to-order & Local & Craft & 2 & \\
\hline Buy-to-order & Local & Job shop & 5 & \\
\hline Buy-to-order & Regional & Job shop & 1 & \\
\hline Buy-to-order & National & Job shop & 1 & \\
\hline Buy-to-order & National & Factory & 2 & \\
\hline Make-to-order & Personal & Craft & 8 & \\
\hline Make-to-order & Local & Craft & 3 & \\
\hline Make-to-order & Local & Job shop & 25 & \\
\hline Make-to-order & Local & Factory & 2 & \\
\hline Make-to-order & Regional & Job shop & 1 & \\
\hline Make-to-order & National & Job shop & 9 & \\
\hline Make-to-order & National & Factory & 4 & \\
\hline Make-to-order & Mobile & Job shop & 9 & \\
\hline Assemble-to-order & Local & Job shop & 2 & Table VI. \\
\hline Assemble-to-order & National & Factory & 3 & Combinations of \\
\hline Make-to-stock & Local & Job shop & 1 & scenarios discovered \\
\hline Make-to-stock & National & Factory & 3 & in literature \\
\hline
\end{tabular}

3D printing the future

1003 


\section{IJPDLM} 47,10

\section{4}

Figure 5.

Coded findings of literature review (circle size directly proportional to the quantity of scenarios for each case)
Figure 6.

The "white space" of $3 \mathrm{D}$ printing supply chain scenarios

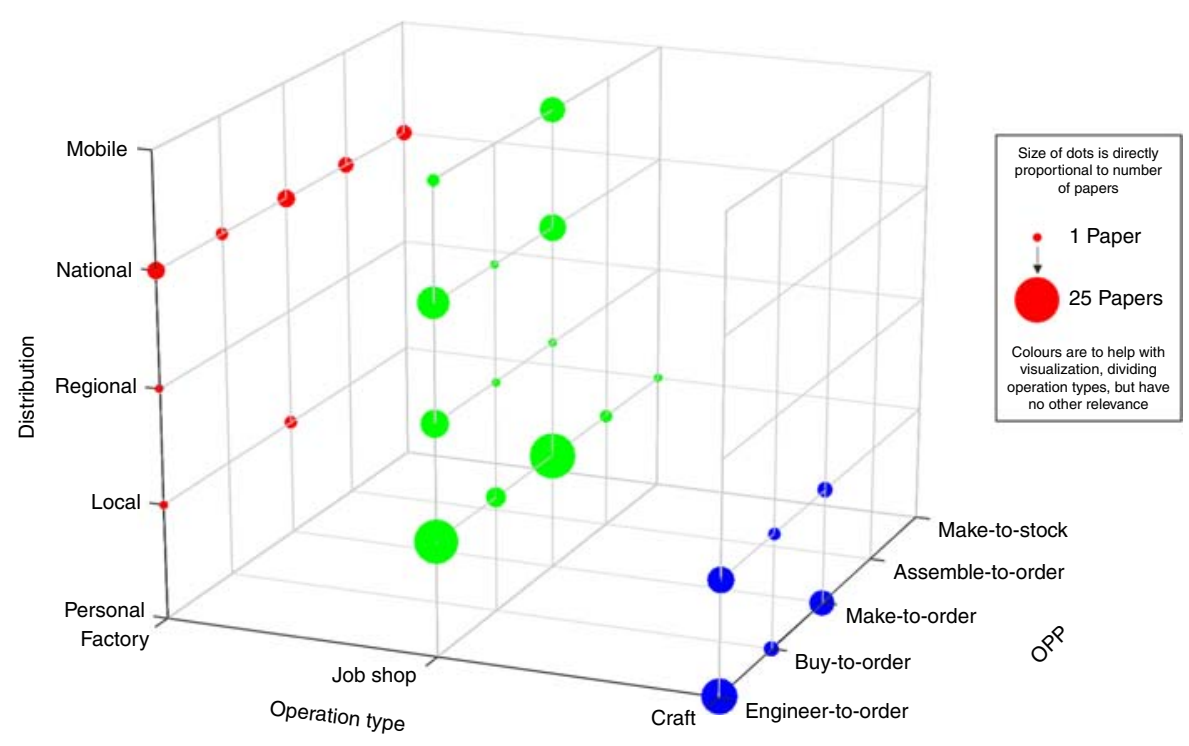

scenarios within the "white space" are few (on average, less than one scenario per combination of elements). By identifying these, it is possible to consider a range of future research opportunities, although some "white spaces" are unlikely to be feasible when applied given the combination of variables considered. A pictorial overview of the "white space" is shown in Figure 6. Each of the "white spaces" is now elaborated upon, accompanied by potential implications for logistics and operations management. However, it is not the intention to develop fully formed scenarios, but propose future research directions.

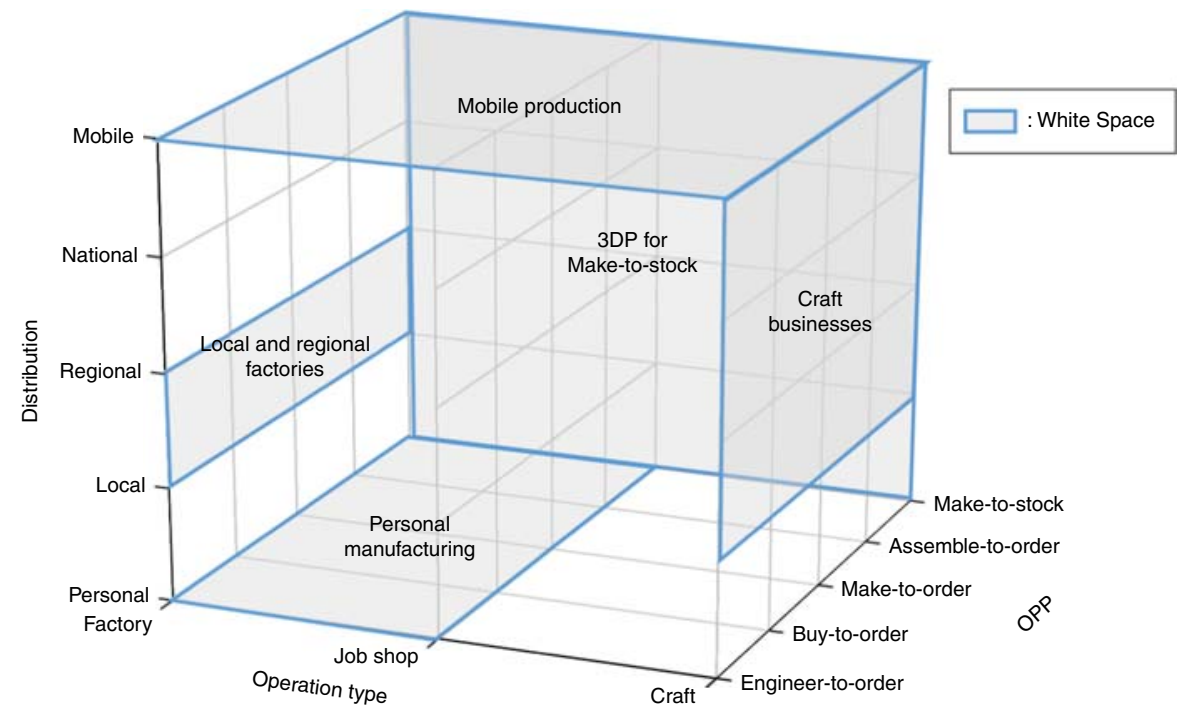




\section{Mobile production}

Mobile manufacturing allows the production system to be located close to demand as it is needed, and relocated to other locations as appropriate. By extension, it is feasible that the production system can be operational whilst in transit, allowing products to be made whilst the traditional delivery process is occurring. This is uncommon for conventional manufacturing, however Amazon have recently filed a patent for a system which performs 3DP in transit (Amazon Technologies, Inc., 2015).

Of the limited existing literature that considers mobile production, the focus has concerned spare part production and use in the construction industry (in both terrestrial and extra-terrestrial applications). In all the cases reviewed, a job shop type operation has been specified, suggesting low volume production, but specialised equipment and processes. Spare parts production is often cited in harsh environments, such as battlefields (Hargreaves, 2009) or in space, and by its nature acts as an on-demand production system. Aside from the work of Mcginley (2015), which discusses a different design philosophy for buildings which uses the design freedoms associated with 3DP production, the use of 3DP in construction is concerned with extra-terrestrial structures, which are highly specialized but will be required in low volumes (Rousek et al., 2012; Cesaretti et al., 2014; Kading and Straub, 2015; Menezes et al., 2015; Montes et al., 2015).

A wider adoption of mobile 3DP has the potential to offer several important advantages in terms of lead-time reduction and manufacturing capacity flexibility compared to other scenarios. By moving production geographically close to demand, transport time that is normally considered a waste either becomes value-adding, or is eliminated entirely (Mason and Lalwani, 2006). Applications could range from a single machine within a van through to a container fitted out with multiple AM machines. Given that the role of third-party logistics providers has evolved to enable increased value-adding services to be offered (Günter Prockl et al., 2012), being able to provide mobile manufacturing options during the course of deliveries (such as for urgent requests) could be an additional value-adding service. While 3PLs such as Panalpina and UPS are currently developing AM services (Amling, 2016; Todd, 2016), these are based upon fixed machines.

Capacity flexibility in manufacturing is normally difficult to achieve (Eyers, 2015), but mobile 3DP may offer important opportunities to enable it. For Factory implementations, the expensive nature of 3DP equipment typically requires firms to ensure high utilisation rates in order to be cost effective (Ruffo and Hague, 2007), and so firms normally avoid excess capacity. By using mobile facilities, addition 3DP equipment can be added or removed to the production system, enabling the achievement of capacity flexibility for the firm. Alternatively, factory mobile 3DP could provide emergency cover for machine failures. For craft implementations, this ability to increase capacity though mobile 3DP might even serve to undermine some of the "print at home" scenarios, by eliminating the need for the customer to own a fixed resource. Just as domestic customers today may hire expensive capital equipment items for short periods (e.g. professional carpet cleaning machines), Mobile 3DP allows customers to increase their ability (from zero to whatever is required), without the need for long-term commitment. This is particularly sensible for home environments, where ownership of high-cost 3DP equipment with low utilisation is likely to be financially unviable.

In terms of future research, there are several aspects related to this scenario that need further investigation. From an engineering perspective, the current AM machine technology is based upon the equipment being static during production. However, mobile AM production could require objects to be produced while the machine is on the move. Therefore, developing equipment to enable this to occur is necessary. Potential business models are another area of further research, to identify approaches that will prove to be
3D printing the future

1005 
IJPDLM

47,10

successful in the marketplace, be that based around leasing the equipment or a "pay as you go" model. Consideration should also be given as to whether STS configurations could be enabled more effectively through 3DP technology.

\section{DP for MTS}

3DP for MTS involves producing parts (or products) without a firm customer order.

By definition, this makes such parts "standardized" rather than "customised", since there is no engagement from the customer within the manufacturing process. The work of Olhager (2003), and later Gosling et al. (2007), positions the OPP after the final assembly of the product in an MTS scenario, allowing no space in the supply chain for customizations by the customer.

In many situations, 3DP for MTS runs contrary to many of the fundamental advantages often perceived for these technologies, and particularly those around customisation (e.g. Gao et al., 2015) and lead time reduction (Hopkinson et al., 2006). With these advantages lost, it is reasonable to question whether 3DP for MTS is a valid scenario, however several studies have highlighted practical opportunities that may be exploited. Olhager (2003) does, however, state that MTS might be more appropriate than MTO when production times are long; as with conventional production technologies, by having products ready to ship MTS can be employed to reduce lead times for customers. Whilst 3DP is often identified as being a fast production technology, in practice machine cycle times mean that multi-day lead times are commonplace, and so in competitive markets MTS may be a necessary requirement. As with conventional manufacturing technologies, if demand is predictable, products are standardized, and practical challenges of stock holding can be overcome, MTS 3DP is certainly a viable proposition. To some extent, in this case 3DP just becomes another manufacturing technology, replacing what is currently used. There would appear to be particular advantages in this compared to tool-based technologies, with 3DP potentially saving on changeover time.

MTS can also be employed to reduce overall production costs experienced in a factory performing MTO. By utilising excess production capacity (either spare space in a build chamber or unutilized machine resources), firms can produce stock items alongside ETO/MTO products (Eyers, 2015). Since 3DP equipment is expensive and machine depreciation represents a substantial overall cost of production (Ruffo and Hague, 2007), such practices can yield competitive benefits for operations.

There are multiple future research opportunities for scenarios in this "white space", again both engineering and managerial. In the case of the former, the continued development of the technology should enable reductions in operating costs and improvements in the speed of production. From a managerial perspective, there is a need for a more comprehensive understanding of the costs of 3DP and their comparison to other technologies. While some articles (such as Chiu and Lin, 2016; Jia et al., 2016) do provide this, there are still many assumptions and unknowns that can be researched further. By understanding these costs, the viability of MTS production scenarios can be fully grasped.

\section{Local and regional factories}

The existing scenarios involving factory scale use of AM equipment are focussed upon facilities that provide a national level of coverage, such as Sasson and Johnson (2016) who highlight the use of a single facility as a manufacture's sole source for production of high-value aircraft components. The rationale behind this is the need to generate enough volume to be able to justify the investment in AM machines and generate a worthwhile economic return.

However, there are opportunities for factory-based production to have a more local and regional perspective as well. There will be locations, such as large urban areas, where 
demand is sufficient to justify investment in dedicated AM facilities. Determining the viability of such a facility is likely to be inherent upon the trade-offs between inventory and transport costs in the supply chain, in much the same way as for the introduction of regional distribution centres into retail distribution during the 1980s (Fernie et al., 2010). Where a product has a high transport cost (relative to its value), then more localised production may make more sense. An alternative may be to take a "contract manufacturing" role within supply chains, whereby the AM facility provides outsourced capacity close to key markets and is used by a range of different customers, thereby aggregating demand and creating the economies needed for viability.

Future research in this area can build on the centralised/decentralised and redistributed manufacturing literature, providing additional scenarios for evaluation based around both the operational costs and also the degree of customisation of products. A fuller understanding of overall supply chain costs, from the supply of raw materials through to the delivery to the customer is needed, as much research currently focusses on the downstream supply chain from production.

\section{Craft businesses}

At the other end of the manufacturing scale when compared to factories, are craft businesses. Unlike the other "white spaces", this region does to some extent already exist. In effect, this business model is an extension of the artisan manufacturing approach that predates modern manufacturing methods (Bunnell, 2004). Craft businesses produce items at home for sale to a wider market. In doing so, they are often exploiting their own creative skills in developing products for wider sale. As a form of self-employment, they have few fixed assets and their profits are for household consumption (Haan, 2002).

However, technological changes have meant that there are increased sales opportunities for these businesses (Cheng et al., 2014). The products may be sold locally through, for example, craft fairs or can be sold to a wider audience (regionally or nationally) either directly through the internet or via a marketplace such as Etsy or eBay. Regardless of the distribution channel, the item would be 3D printed and, where sold remotely, then dispatched with a parcel carrier to the customer. In this context, it is not the 3DP that enables the regional and national sales, but the wider "system" within which it is positioned.

Craft businesses present a range of future research opportunities. From a managerial perspective, identifying different business models and the range of products and services offered would show how such operations complement the more "industrial" players in the market (Rogers et al., 2016), and where the boundary is with job shop operations. There is also a policy aspect to future research, by defining the value created for local economies by such businesses. As Aldrick (2016) notes, the calculation of gross domestic product (GDP) does not fully capture changes to value creation due to technology. Such work is often known as the "hidden economy" (Williams, 2004). Policy-oriented research in this area will give a better indication of the value of craft-based manufacturing to the economy.

\section{Personal manufacturing}

Personal manufacturing forms another group of potential scenarios, where both production and consumption would take place within the user's home. However, the scale of production is significantly larger than just a domestic printer, suggesting that home manufacturing requires a job-shop or factory production facility in each home and potentially storage for work in progress (with an ATO approach) or finished goods (with a MTO strategy). The physical constraints of housing this amount of equipment within a domestic environment, and the technical constrains of operating such equipment require careful consideration as to their feasibility.
$3 \mathrm{D}$ printing the future 
IJPDLM

47,10

1008

With no existing scenarios, it is debateable whether a domestic setting could produce sufficient demand for such a production method to become feasible, and comparisons to existing production and distribution methods are required to prove whether this is more cost effective for such items. However, if the user was looking to constantly maximise the use of the build chamber during each production run, or to produce some "consumable" items that could be produced in this manner there may be situation where this occurs. It is also yet to be determined whether such use of 3DP machines is an efficient use of the technology.

These "white spaces" are summarised in Table VII, along with the suggestions for future research directions. There are also wider supply chain management issues that are pertinent across all of the areas of "white space". In many cases, there are significant changes to the nature of manufacturing systems, and the wider environmental implications of this need consideration, although any evaluation is likely to be contingent on the specific nature of future scenarios. There are also issues around whether to insource or outsource 3DP capabilities, particularly in more decentralised or redistributed situations where capital expenditure may be greater. Aligned with this, relationships with suppliers in outsourced situations need careful consideration, reflecting power/dependency factors as well as issues of product quality.

\section{Conclusion}

The motivation for this paper arose from the recognition that, while many future scenarios proposed for 3DP have been proposed by both academics and practitioners, little explicit focus had been given to supply chains. It was recognised that potential scenarios were scattered within literature crossing many disciplines, yet often appeared to have commonalities between them. Equally, it was identified that there were potential scenarios that had not been considered within the literature. Therefore, the aim of the paper was to identify the "white space" of existing 3DP supply chain scenarios and consider the feasibility of 3DP being able to fill this gap.

To address this aim, a structured literature review has been carried out across six databases and covering a range of different publications. In total, 201 distinct scenarios

\begin{tabular}{ll}
\hline White space & Future research questions \\
\hline Mobile 3DP & Can 3DP equipment produce items in transit? \\
& $\begin{array}{l}\text { What business models/propositions exist for mobile capacity? } \\
\text { How can 3PLs exploit this opportunity? }\end{array}$ \\
& Would 3DP support ship-to-stock configurations? \\
3DP for MTS & How can 3DP processes be made quicker and cheaper? \\
& Can 3DP offer comparable costs to existing manufacturing technology? \\
& How can production scheduling exploit MTS and MTO capabilities of 3DP? \\
Local and & In which situations are decentralised or redistributed supply chains exploiting \\
regional & 3DP appropriate? \\
factories & Can 3DP offer comparable supply chain costs to existing manufacturing technology? \\
Craft businesses & What trade-offs exist between transport and inventory? \\
& What business models exist for craft operations? \\
& How applicable are existing SCM theories to these operations? \\
& Is 3DP the most important aspect of the supply chain system in enabling these scenarios? \\
What is the GDP value of the 3DP enabled hidden economy? \\
Personal & Does a household create sufficient demand for this to be a viable methodology? \\
manufacturing & Will technology develop to allow reliable manufacturing at home? \\
& Is this an efficient use of a home 3DP system? \\
& Is it feasible to run a manufacturing operation on this scale?
\end{tabular}

Table VII.

Summary of "white space” findings 
were identified through this search, and these were coded against criteria to examine the $\mathrm{OPP}$, distribution of manufacturing and scale of operations. From this coding, it was clear that many scenarios considered 3DP to be used in supply chains driven by customer demand (make to order, BTO, ETO) and in a job shop production environment. Interestingly, the geography of applications was more spread, perhaps reflecting the ease with which 3DP products can be distributed.

From this assessment, five areas of "white space" within existing scenarios were identified Of these, four were considered feasible and offer valuable opportunities for extending existing research. For MTS and national and regional factories, the existing technology could be used to facilitate their operationalisation, although questions exist around the economics of such approaches. By contrast, mobile production is likely to require some further technological development as well as research into viable business models. Craft businesses to some extent already exist but are part of the hidden economy. In this case, research focussed on such organisations can provide valuable insights to complement the current focus on more industrial applications. The remaining "white space" suggests manufacturing at scale in the home. As this is significantly different from current manufacturing practices a great deal of future investigation into its feasibility would be required.

This work contributes to the existing literature on 3DP supply chains by consolidating the diverse body of scenarios and reflecting upon their alignment to existing supply chain theory. We have developed a research agenda identifying areas where current thinking on 3DP has not ventured in so much detail, such as mobile factories, personal manufacturing and craft businesses. In doing so, the paper provides directions for future research, particularly in these underresearched areas, although there remains a need for further development in the more established scenario options. This work has considered just three dimensions of supply chain structure against which to compare the scenarios, and considering other strategically important aspects of 3DP supply chain scenarios, such as flexibility, constitute other areas of future research.

\section{References}

Achillas, C., Aidonis, D., Iakovou, E., Thymianidis, M. and Tzetzis, D. (2015), "A methodological framework for the inclusion of modern additive manufacturing into the production portfolio of a focused factory", Journal of Manufacturing Systems, Vol. 37, Part 1, pp. 328-339.

Aldrick, P. (2016), "GDP is past its sell-by date when it comes to measuring productivity", The Times, 6 December, available at: www.thetimes.co.uk/article/gdp-is-past-its-sell-by-date-when-it-comesto-measuring-productivity-58q05tcgs (accessed 21 December 2016).

All3dp (2016), “20 best cheap 3D printers under $\$ 500 / \$ 1000$ in winter 2016”, available at: https://all3dp. com/best-cheap-budget-3d-printer-affordable-under-1000-budget (accessed 1 December 2016).

Amazon Technologies, Inc. (2015), "Providing services related to item delivery via 3D manufacturing on demand", available at: www.google.com/patents/US20150052024 (accessed 21 December 2016).

Amling, A. (2016), "UPS and SAP push on-demand 3D printing", available at: http://fortune.com/2016/ 05/18/sap-and-ups-3d-printing/ (accessed 21 December 2016).

Anonymous (2006), "LEGACY 2156: rapid manufacturing”, The Engineer, London, 11 December, p. 25.

Barz, A., Buer, T. and Haasis, H.D. (2016), "A study on the effects of additive manufacturing on the structure of supply networks", IFAC-PapersOnLine, Vol. 49 No. 2, pp. 72-77.

Baumers, M., Dickens, P., Tuck, C. and Hague, R. (2016), "The cost of additive manufacturing: machine productivity, economies of scale and technology-push", Technological Forecasting and Social Change, Vol. 102, pp. 193-201.

Bedinger, M., Walker, G.H., Piecyk, M. and Greening, P. (2016), "21st century trucking: a trajectory for ergonomics and road freight", Applied Ergonomics, Vol. 53, Part B, pp. 343-356.
3D printing the future

1009 
IJPDLM

47,10

1010

Birtchnell, T. and Urry, J. (2013), “3D, SF and the future”, Futures, Vol. 50, pp. 25-34.

Birtchnell, T., Urry, J., Cook, C. and Curry, A. (2013), "Freight Miles. The impacts of 3D printing on transport and society", Economic \& Social Research Council (ESRC) Project ES/J007455/1, Lancaster University, Lancaster.

Bishop, P., Hines, A. and Collins, T. (2007), "The current state of scenario development: an overview of techniques", Foresight, Vol. 9 No. 1, pp. 5-25.

Bogers, M., Hadar, R. and Bilberg, A. (2016), "Additive manufacturing for consumer-centric business models: implications for supply chains in consumer goods manufacturing", Technological Forecasting and Social Change, Vol. 102, pp. 225-239.

Bunnell, K. (2004), "Craft and digital technology", World Craft Council 40th Annual Conference, Metsovo, 2 May.

Cautela, C., Pisano, P. and Pironti, M. (2014), "The emergence of new networked business models from technology innovation: an analysis of 3D printing design enterprises", International Entrepreneurship and Management Journal, Vol. 10 No. 3, pp. 487-501.

Cesaretti, G., Dini, E., De Kestelier, X., Colla, V. and Pambaguian, L. (2014), "Building components for an outpost on the lunar soil by means of a novel 3D printing technology", Acta Astronautica, Vol. 93, pp. 430-450.

Chen, D.F., Heyer, S., Ibbotson, S., Salonitis, K., Steingrimsson, J.G. and Thiede, S. (2015), "Direct digital manufacturing: definition, evolution, and sustainability implications", Journal of Cleaner Production, Vol. 107, pp. 615-625.

Cheng, J.-S., Li, F.-C., Ou, T.-Y. and Kung, C.-C. (2014), "The strategic research on integrating service model for SMEs cloud supply chain in Taiwan", International Journal of Electronic Business Management, Vol. 12 No. 1, pp. 33-40.

Chiu, M.C. and Lin, Y.H. (2016), "Simulation based method considering design for additive manufacturing and supply chain: an empirical study of lamp industry", Industrial Management \& Data Systems, Vol. 116 No. 2, pp. 322-348.

CILT (2011), "Vision 2035: a report on the future of logistics and transport in the UK", Chartered Institute of Logistics and Transport (UK), Corby, available at: http://bit.ly/2gGN1nT (accessed 17 November 2016).

CIPS Knowledge (2013), CIPS Position on Practice: Using Local Suppliers, Charterd Institute of Purchasing \& Supply, Stamford, available at: www.cips.org/Documents/Knowledge/ Procurement-Topics-and-Skills/5-Strategy-and-Policy/Models-SC-Sourcing-Procurement-Costs/ POP-Using_Local_Suppliers.pdf (accessed 12 December 2016).

Cotteleer, M.J. and Deloitte Services Llp (2014), "3D opportunity: additive manufacturing paths to performance, innovation, and growth", Southeastern Institute of Manufacturing and Technology Additive Manufacturing Symposium Florence, SC, 1 October.

Crump, S.S. and Stratasys, Inc. (1992), "Apparatus and Method for Creating three-dimensional Objects”, U.S. Patent No. 5,121,329, 9 June.

Cusumano, M.A. (1992), "Shifting economies - from craft production to flexible systems and software factories", Research Policy, Vol. 21 No. 5, pp. 453-480.

Darkow, I.L. (2015), "The involvement of middle management in strategy development - development and implementation of a foresight-based approach", Technological Forecasting and Social Change, Vol. 101, pp. 10-24.

DHL (2012), Delivering Tomorrow: Logistics 2050 - A Scenario Study, Deutsche Post AG, Bonn, available at: www.dhl.com/content/dam/Local_Images/g0/aboutus/SpecialInterest/Logistics20 50/szenario_study_logistics_2050.pdf (accessed 1 December 2016).

Duray, R., Ward, P.T., Milligan, G.W. and Berry, W.L. (2000), “Approaches to mass customization: configurations and empirical validation”, Journal of Operations Management, Vol. 18 No. 6, pp. $605-625$.

Easton, T.A. (2009), "The design economy: a brave new world for businesses and consumers”, Futurist, Vol. 43 No. 1, pp. $42-47$. 
Eyers, D.R. (2015), The Flexibility of Industrial Additive Manufacturing Systems, Cardiff University, Cardiff.

Eyers, D.R. and Potter, A.T. (2015), "E-commerce channels for additive manufacturing: an exploratory study", Journal of Manufacturing Technology Management, Vol. 26 No. 3, pp. 390-411.

Ferguson, S.M., Olewnik, A.T. and Cormier, P. (2014), "A review of mass customization across marketing, engineering and distribution domains toward development of a process framework", Research in Engineering Design, Vol. 25 No. 1, pp. 11-30.

Fernie, J., Sparks, L. and Mckinnon, A.C. (2010), "Retail logistics in the UK: past, present and future", International Journal of Retail \& Distribution Management, Vol. 38 Nos 11/12, pp. 894-914.

Ford, S. and Despeisse, M. (2016), "Additive manufacturing and sustainability: an exploratory study of the advantages and challenges”, Journal of Cleaner Production, Vol. 137, pp. 1573-1587.

Frankel, R., Naslund, D. and Bolumole, Y. (2005), "The 'white space' of logistics research: a look at the role of methods usage", Journal of Business Logistics, Vol. 26 No. 2, pp. 185-209.

Gao, W., Zhang, Y., Ramanujan, D., Ramani, K., Chen, Y., Williams, C.B., Wang, C.C.L., Shin, Y.C., Zhang, S. and Zavattieri, P.D. (2015), "The status, challenges, and future of additive manufacturing in engineering", Computer-Aided Design, Vol. 69, pp. 65-89.

Garrett, B. (2014), “3D printing: new economic paradigms and strategic shifts”, Global Policy, Vol. 5 No. 1, pp. 70-75.

Gebbe, C., Hilmer, S., Gotz, G., Lutter-Gunther, M., Chen, Q., Unterberger, E., Glasschroder, J., Schmidt, V., Riss, F., Kamps, T., Tammer, C., Seidel, C., Braunreuther, S. and Reinhart, G. (2015), “Concept of the green factory Bavaria in Augsburg", 5th Conference on Learning Factories, Vol. 32, pp. 53-57.

Gosling, J., Naim, M.M., Fowler, N. and Fearne, A. (2007), "Manufacturers' preparedness for agile construction", The IET International Conference on Agile Manufacturing (ICAM 2007), IET, Durham, 9-11 July.

Günter Prockl, G., Pflaum, A. and Kotzab, H. (2012), "3PL factories or lernstatts? Value-creation models for 3PL service providers", International Journal of Physical Distribution \& Logistics Management, Vol. 42 No. 6, pp. 544-561.

Haan, H.C. (2002), "Training for work in the informal sector: new evidence from Kenya, Tanzania and Uganda. ILO", Focus Programme on Skills, Knowledge and Employability, Series on the Informal Economy, International Labour Office, Geneva.

Hargreaves, B. (2009), “Quick fix”, Professional Engineering, Vol. 22 No. 1, pp. 35-36.

Hayes, R.H. and Wheelwright, S.C. (1979), "Link manufacturing process and product life-cycles", Harvard Business Review, Vol. 57 No. 1, pp. 133-140.

Holmstrom, J. and Partanen, J. (2014), "Digital manufacturing-driven transformations of service supply chains for complex products", Supply Chain Management-An International Journal, Vol. 19 No. 4 , pp. 421-430.

Holmström, J., Partanen, J., Tuomi, J. and Walter, M. (2010), "Rapid manufacturing in the spare parts supply chain: alternative approaches to capacity deployment", Journal of Manufacturing Technology Management, Vol. 21 No. 6, pp. 687-697.

Hopkinson, N., Hague, R. and Dickens, P. (2006), Rapid Manufacturing: An Industrial Revolution for the Digital Age, John Wiley \& Sons, Chichester.

Jia, F., Wang, X.F., Mustafee, N. and Hao, L. (2016), "Investigating the feasibility of supply chain-centric business models in 3D chocolate printing: a simulation study", Technological Forecasting and Social Change, Vol. 102, pp. 202-213.

Jiang, R., Kleer, R. and Piller, F.T. (2017), "Predicting the future of additive manufacturing: a Delphi study on economic and societal implications of 3D printing for 2030", Technological Forecasting and Social Change, Vol. 117, pp. 84-97.

Jones, R., Haufe, P., Sells, E., Iravani, P., Olliver, V., Palmer, C. and Bowyer, A. (2011), "RepRap - the replicating rapid prototyper", Robotica, Vol. 29 No. 1, pp. 177-191. 
IJPDLM

47,10
Kading, B. and Straub, J. (2015), "Utilizing in-situ resources and 3D printing structures for a manned Mars mission”, Acta Astronautica, Vol. 107, pp. 317-326.

Khajavi, S.H., Partanen, J. and Holmström, J. (2014), "Additive manufacturing in the spare parts supply chain", Computers in Industry, Vol. 65 No. 1, pp. 50-63.

Khajavi, S.H., Partanen, J., Holmström, J. and Tuomi, J. (2015), "Risk reduction in new product launch: a hybrid approach combining direct digital and tool-based manufacturing", Computers in Industry, Vol. 74, pp. 29-42.

Lampel, J. and Mintzberg, H. (1996), “Customizing customization”, Sloan Management Review, Vol. 38 No. 1, pp. 21-30.

Liu, P., Huang, S.H., Mokasdar, A., Zhou, H. and Hou, L. (2014), "The impact of additive manufacturing in the aircraft spare parts supply chain: supply chain operation reference (SCOR) model based analysis", Production Planning \& Control, Vol. 25 Nos 13/14, pp. 1169-1181.

McGinley, T. (2015), “A morphogenetic architecture for intelligent buildings", Intelligent Buildings International, Vol. 7 No. 1, pp. 4-15.

Mason, R.J. and Lalwani, C. (2006), "Transport integration tools for supply chain management", International Journal of Logistics: Research and Applications, Vol. 9 No. 1, pp. 57-74.

Mavri, M. (2015), "Redesigning a production chain based on 3D printing technology", Knowledge and Process Management, Vol. 22 No. 3, pp. 141-147.

Menezes, A.A., Cumbers, J., Hogan, J.A. and Arkin, A.P. (2015), "Towards synthetic biological approaches to resource utilization on space missions", Journal of the Royal Society Interface, Vol. 12 No. 102, pp. 1-20.

Merrill, P. (2014), “The new revolution”, Quality Progress, Vol. 47 No. 1, pp. 50-52.

Montelisciani, G., Mazzei, D. and Fantoni, G. (2014), "How the next generation of products pushes to rethink the role of users and designers", Procedia CIRP, Vol. 21, pp. 93-98.

Montes, C., Broussard, K., Gongre, M., Simicevic, N., Mejia, J., Tham, J., Allouche, E. and Davis, G. (2015), "Evaluation of lunar regolith geopolymer binder as a radioactive shielding material for space exploration applications", Advances in Space Research, Vol. 56 No. 6, pp. 1212-1221.

Monzon, M.D., Ortega, Z., Martinez, A. and Ortega, F. (2015), "Standardization in additive manufacturing: activities carried out by international organizations and projects", International Journal of Advanced Manufacturing Technology, Vol. 76 Nos 5/8, pp. 1111-1121.

Moser, H. (2011), "Reshoring initiative spearheads effort to bring back US manufacturing", Modern Applications News, Vol. 5 No. 12, p. 8.

Narasimhan, R. and Carter, J.R. (1990), “Organisation, communication and co-ordination of internaional sourcing", International Marketing Review, Vol. 7 No. 2, pp. 6-20.

Nickels, L. (2015), “AM and aerospace: an ideal combination”, Metal Powder Report, Vol. 70 No. 6, pp. 300-303.

Noriega, F.M., Gaterman, H. and Alvarez, E.R. (2010), "Collaborative 3D modelling and printing: what you see is not directly what you get", Ecaade: Future Cities, pp. 31-40.

O’Brien, F.A. (2004), "Scenario planning - lessons for practice from teaching and learning”, European Journal of Operational Research, Vol. 152 No. 3, pp. 709-722.

Olhager, J. (2003), "Strategic positioning of the order penetration point", International Journal of Production Economics, Vol. 85 No. 3, pp. 319-329.

Ostuzzi, F., Rognoli, V., Saldien, J. and Levi, M. (2015), “+TUO project: low cost 3D printers as helpful tool for small communities with rheumatic diseases”, Rapid Prototyping Journal, Vol. 21 No. 5, pp. 491-505.

Park, K. (2015), “3D printing of 5-drug polypill”, Journal of Controlled Release, Vol. 217, p. 352.

Pasluosta, C.F., Gassner, H., Winkler, J., Klucken, J. and Eskofier, B.M. (2015), "An emerging era in the management of Parkinson's disease: wearable technologies and the internet of things", IEEE Journal of Biomedical and Health Informatics, Vol. 19 No. 6, pp. 1873-1881. 
Petrick, I.J. and Simpson, T.W. (2013), "3D printing disrupts manufacturing how economies of one create new rules of competition", Research-Technology Management, Vol. 56 No. 6, pp. 12-16.

Potstada, M. and Zybura, J. (2014), "The role of context in science fiction prototyping: the digital industrial revolution”, Technological Forecasting and Social Change, Vol. 84, pp. 101-114.

Prince, J.D. (2014), “3D printing: an industrial revolution”, Journal of Electronic Resources in Medical Libraries, Vol. 11 No. 1, pp. 39-45.

Rayna, T. and Striukova, L. (2014), "The impact of 3D printing technologies on business model innovation", in Benghozi, P.J., Krob, D., Lonjon, A. and Panetto, H. (Eds), Digital Enterprise Design \& Management: Proceedings of the Second International Conference on Digital Enterprise Design and Management DED\&M, Springer International Publishing, Cham, pp. 119-132.

Reiter, S. (1966), “A system for managing job-shop production”, The Journal of Business, Vol. 39 No. 3, pp. 371-393.

Rogers, H., Baricz, N. and Pawar, K. (2016), "3D printing services: classification, supply chain implications and research agenda", International Journal of Physical Distribution \& Logistics Management, Vol. 46 No. 10, pp. 886-907.

Rousek, T., Eriksson, K. and Doule, O. (2012), “SinterHab”, Acta Astronautica, Vol. 74, pp. 98-111.

Ruffo, M. and Hague, R. (2007), "Cost estimation for rapid manufacturing - simultaneous production components using laser of mixed sintering", Proceedings of the Institution of Mechanical Engineers Part B-Journal of Engineering Manufacture, Vol. 221 No. 11, pp. 1585-1591.

Rushton, A., Croucher, P. and Baker, P. (2014), The Handbook of Logistics and Distribution Management: Understanding the Supply Chain, Kogan Page Publishers, London.

Saenz, M.J. and Koufteros, X. (2015), "Special issue on literature reviews in supply chain management and logistics", International Journal of Physical Distribution \& Logistics Management, Vol. 45 Nos 1/2, pp. 2-15.

Sasson, A. and Johnson, J.C. (2016), "The 3D printing order: variability, supercenters and supply chain reconfigurations", International Journal of Physical Distribution \& Logistics Management, Vol. 46 No. 1, pp. 82-94.

Schoemaker, P.J.H. and Mavaddat, V.M. (2000), "Scenario planning for disruptive technologies”, in Day, G.S., Schoemaker, P.J.H. and Gunther, R.E. (Eds), Wharton on Managing Emerging Technologies, John Wiley \& Sons, Inc., New York, NY, pp. 206-241.

Scholz, S., Mueller, T., Plasch, M., Limbeck, H., Adamietz, R., Iseringhausen, T., Kimmig, D., Dickerhof, M. and Woegerer, C. (2016), "A modular flexible scalable and reconfigurable system for manufacturing of microsystems based on additive manufacturing and e-printing", Robotics and Computer-Integrated Manufacturing, Vol. 40, pp. 14-23.

Schubert, C., Van Langeveld, M.C. and Donoso, L.A. (2014), "Innovations in 3D printing: a 3D overview from optics to organs", British Journal of Ophthalmology, Vol. 98 No. 2, pp. 159-161.

Schwarz, P. (1991), The Art of the Long View: Planning for the Future in an Uncertain World, Currency Doubleday, New York, NY.

Scott, A. and Harrison, T.P. (2015), "Additive manufacturing in an end-to-end supply chain setting", 3D Printing and Additive Manufacturing, Vol. 2 No. 2, pp. 65-77.

Senyana, L. and Cormier, D. (2014), "An environmental impact comparison of distributed and centralized manufacturing scenarios", in Li, D., Zheng, D. and Shi, J. (Eds), Materials Research and Applications, Parts 1-3, Trans Tech Publications, Zurich, pp. 1449-1453.

Seuring, S. and Gold, S. (2012), "Conducting content-analysis based literature reviews in supply chain management”, Supply Chain Management: An International Journal, Vol. 17 No. 5, pp. 544-555.

Shapiro, J.F. (2004), "Challenges of strategic supply chain planning and modeling", Computers \& Chemical Engineering, Vol. 28 Nos 6/7, pp. 855-861.

Sharman, G. (1984), "The rediscovery of logistics”, Harvard Business Review, Vol. 62 No. 5, pp. 71-79.
3D printing the future 
IJPDLM 47,10
Silva, J.V.L. and Rezende, R.A. (2013), "Additive manufacturing and its future impact in logistics", IFAC Proceedings Volumes, Vol. 46 No. 24, pp. 277-282.

Sodhi, M. (2003), "How to do strategic supply-chain planning”, Sloan Management Review, Vol. 45 No. 1 , pp. 69-75.

Srai, J.S., Harrington, T.S. and Tiwari, M.K. (2016), "Characteristics of redistributed manufacturing systems: a comparative study of emerging industry supply networks", International Journal of Production Research, Vol. 54 No. 23, pp. 6936-6955.

Srougi, V., Chambo, J.L. and Srougi, M. (2016), “Author reply”, Urology, Vol. 90, p. 221.

Stillstrom, C. and Jackson, M. (2007), "The concept of mobile manufacturing”, Journal of Manufacturing Systems, Vol. 26 Nos 3/4, pp. 188-193.

Storper, M. and Harrison, B. (1991), "Flexibility, hierarchy and regional-development - the changing structure of industrial-production systems and their forms of governance in the 1990s", Research Policy, Vol. 20 No. 5, pp. 407-422.

Stuart, N. and Excell, J. (2010), “Additive manufacturing: dream machines”, The Engineer, 24 May, pp. 22-26.

Taylor, P. (2012), "Emerging tech: what is hot in", available at: www.FT.com (accessed 5 July 2016).

The Economist (2011), "3D printing: the printed world", The Economist, 10 February, available at: www.economist.com/node/18114221 (accessed 21 December 2016).

Todd, S. (2016), "Panalpina forges strategic partnership in 3D printing", available at: www.lloydsloadinglist.com/freight-directory/news/Panalpina-forges-strategic-partnership-in3D-printing/67076.htm (accessed 21 December 2016).

Tranfield, D., Denyer, D. and Smart, P. (2003), "Towards a methodology for developing evidence-informed management knowledge by means of systematic review", British Journal of Management, Vol. 14 No. 3, pp. 207-222.

Tuck, C.J., Hague, R.J.M., Ruffo, M., Ransley, M. and Adams, P. (2008), "Rapid manufacturing facilitated customization", International Journal of Computer Integrated Manufacturing, Vol. 21 No. 3, pp. $245-258$.

Van Landeghem, H. and Vanmaele, H. (2002), "Robust planning: a new paradigm for demand chain planning”, Journal of Operations Management, Vol. 20 No. 6, pp. 769-783.

Von Der Gracht, H.A. and Darkow, I.-L. (2010), "Scenarios for the logistics services industry: a Delphi-based analysis for 2025”, International Journal of Production Economics, Vol. 127 No. 1, pp. 46-59.

Wagner, S.M. and Walton, R.O. (2016), "Additive manufacturing's impact and future in the aviation industry”, Production Planning \& Control, Vol. 27 No. 13, pp. 1124-1130.

Williams, C. (2004), The Underground Sector and the Hidden Economy of Favours, Palgrave-Macmillan, Basingstoke.

Wohlers, T.T. and Caffrey, T. (2015), "Wohlers report 2015: 3D printing and additive manufacturing state of the industry annual worldwide progress report", Wohlers Associates, Fort Collins, CO.

Wright, G. and Cairns, G. (2011), Scenario Thinking: Practical Approaches to the Future, Palgrave Macmillan, Basingstoke.

Würtz, G., Lasi, H. and Morar, D. (2015), “Additive manufacturing - enabling technology for lifecycle oriented value-increase or value-decrease”, Procedia CIRP, Vol. 33, pp. 394-399.

\section{Corresponding author}

Michael J. Ryan can be contacted at: ryanm6@cardiff.ac.uk

For instructions on how to order reprints of this article, please visit our website:

www.emeraldgrouppublishing.com/licensing/reprints.htm

Or contact us for further details: permissions@emeraldinsight.com 